\title{
Temperature dependent transitions in excitability predicted by an electrodiffusion model of membrane potential
}

\author{
Juan R Melendez-Alvarez ${ }^{1 *}$, Erin C McKiernan², Marco Arieli Herrera Valdez ${ }^{1,2}$ \\ From Twenty First Annual Computational Neuroscience Meeting: CNS*2012 \\ Decatur, GA, USA. 21-26 July 2012
}

Temperature affects cellular function in different ways that include the transmembrane transport of ions and the kinetics of membrane spanning proteins mediating such transport. Electrodiffusion models of membrane potential $[1,2]$ can be used to study the temperature dependence of the kinetics of the channels and the transmembrane diffusion of ions. In turn, channel kinetics and transmembrane diffusion may cause significant changes in the dynamics of a model neuronal membrane. We constructed a twodimensional biophysical electrodiffusion model to study the specific effects on the excitability profiles of the model neuron as a function of temperature. The formulations of the model allows an analysis that can be interpreted in terms of patterns of ion channel expression [3,4]. A change in the variables of the system unravels the model to be rewritten so that only one of the variables is temperature-dependent. We use bifurcation analysis to map the possible excitability profiles of the model neuron. To do so, we use an external current stimulus as a bifurcation parameter, for a range of temperatures and for different patterns of ion channel expression. The bifurcation structure of the model is used to generate basic intuition and explanations for the respose profiles of the model neuron subject to stimuli that includes square pulses, ramps, and synaptic input. We identify parameter regimes associated with specific patterns of ion channel expression in which the excitability of the membrane undergoes significant changes. We identify possible compensation mechanisms not requiring enzymatic actions that may underlie the regularization of cellular function within the nervous systems of animals exposed to different temperatures.

\footnotetext{
* Correspondence: marco.herrera@upr.edu

'Department of Mathematics and Physics, University of Puerto Rico at Cayey, Cayey, PR, 00736, USA

Full list of author information is available at the end of the article
}

\section{Acknowledgements}

The authors thank faculty and staff of the Institute of Interdisciplinary Research for their support. This work was supported in part by the Building Research Infrastructure and Capacity (BRIC) program at UPR-Cayey (P20 MD006144) through the National Institute of Minority Health and Health Disparities.

\section{Author details}

'Department of Mathematics and Physics, University of Puerto Rico at Cayey, Cayey, PR, 00736, USA. ${ }^{2}$ Institute of Interdisciplinary Research, University of Puerto Rico at Cayey, Cayey, PR, 00736, USA.

Published: 16 July 2012

\section{References}

1. Endresen LP, Hall K, Hoye JS, Myrheim J: A theory for the membrane potential of living cells. European Journal of Biophysics 2000, 29:90-103.

2. Herrera-Valdez MA: Geometry of reduced biophysical models of membrane potential. Dissertation, University of Arizona 2012.

3. Herrera-Valdez MA: Membranes with the same ion channel populations but different excitabilities. In review 2012.

4. Herrera-Valdez MA, McKiernan EC, Berger SD, Ryglewski S, Duch C, Crook S: Relating ion channel expression, bifurcation structure, and diverse firing patterns in a model of an identified motor neuron. In review 2012.

\section{doi:10.1186/1471-2202-13-S1-P85}

Cite this article as: Melendez-Alvarez et al:: Temperature dependent transitions in excitability predicted by an electrodiffusion model of membrane potential. BMC Neuroscience 2012 13(Suppl 1):P85.

Submit your next manuscript to BioMed Central and take full advantage of:

- Convenient online submission

- Thorough peer review

- No space constraints or color figure charges

- Immediate publication on acceptance

- Inclusion in PubMed, CAS, Scopus and Google Scholar

- Research which is freely available for redistribution

\section{() Biomed Central}

